\title{
Modifikasi Perencanaan Struktur Gedung Apartemen Brooklyn Alam Sutera Menggunakan Struktur Komposit Baja-Beton dengan Sistem Rangka Berpengaku Eksentris
}

\author{
Muhammad Zulfikar Fauzi, Endah Wahyuni, dan Budi Suswanto \\ Departemen Teknik Sipil, Fakultas Teknik Sipil, Lingkungan, dan Kebumian, Institut Teknologi \\ Sepuluh Nopember (ITS) \\ e-mail: endah@ce.its.ac.id
}

\begin{abstract}
Abstrak-Struktur komposit merupakan struktur yang terdiri dari dua atau lebih material berbeda sifat dan karakteristik yang berkerja bersama sama untuk memikul beban yang berkerja pada suatu struktur dalam hal ini digunakan material baja dan beton. Struktur komposit baja-beton memungkinkan pemanfaatan karakteristik dasar masing-masing bahan secara optimal, sehingga dengan penampang yang lebih kecil, mampu memikul beban serta dengan bentang yang sama dengan beton bertulang biasa.
\end{abstract}

Gedung Brooklyn Alam Sutra Apartment merupakan gedung yang terdiri dari 19 lantai dan 1 lantai atap yang pada awalnya didesain dengan menggunakan struktur beton bertulang. Perancangan bangunan ini dimodifikasi menggunakan struktur komposit baja-beton. Dalam tugas akhir ini dilakukan perencanaan ulang menggunakan struktur komposit baja-beton dengan Sistem Rangka Bresing Eksentris (SRBE). Kelebihan sistem ini adalah daktilitas struktur yang baik dengan mekanisme kelelehan geser yang terjadi pada link. Link adalah bagian pada elemen struktur balok yang dibentuk oleh perpotongan balok dan bresing.

Telah dilakukan perencanaan struktur gedung menggunakan komposit baja-beton Sistem Rangka Bresing Eksentris (SRBE) yang memenuhi persyaratan keamanan struktur berdasarkan SNI 2847-2013, SNI 03-1729:2002, SNI 1729:2015, SNI 1726:2012, SNI 1727-2013.

Dari analisa dan hasil perhitungan diperoleh hasil yaitu: tebal pelat lantai dan atap bondek $10 \mathrm{~cm}$, dimensi balok induk WF $500 \times 300 \times 11 \times 15$, dimensi balok link WF 600x300x13x24 dengan panjang elemen link $120 \mathrm{~cm}$, dimensi bresing WF 450x300x11x15, dimensi kolom CFT 600x600x25. Perencanaan pondasi menggunakan tiang pancang beton pracetak diameter $80 \mathrm{~cm}$ dengan kedalaman 10 meter. Kolom pedestal direncanakan dengan dimensi $900 \mathrm{~mm}$ x $900 \mathrm{~mm}$. Dan dimensi Sloof $40 \mathrm{~cm}$ x 60 cm.

Kata Kunci-Sistem Rangka Berpengaku Eksentris, Link, Baja, Komposit.

\section{PENDAHULUAN}

$I$ NDONESIA merupakan negara dengan perkembangan jumlah penduduk yang cukup besar di dunia, sehingga kebutuhan akan lahan hunian semakin tinggi. Kebutuhan akan lahan hunian yang semakin tinggi membuat banyaknya pembangunan gedung bertingkat yang disebabkan oleh keterbatasan lahan yang ada. Selain itu, Indonesia merupakan tempat bertemunya lempengan dunia yang menyebabkan
Indonesia menjadi negara rawan gempa. Hal ini menjadi tantangan tersendiri untuk membuat gedung bertingkat yang tahan gempa.

Struktur komposit merupakan struktur yang terdiri dari dua atau lebih material berbeda sifat dan karakteristik yang berkerja bersama sama untuk memikul beban yang berkerja pada suatu struktur, dalam hal ini digunakan material baja dan beton. Perbedaan dengan beton bertulang terdapat pada pemikul gaya tariknya. pada struktur beton bertulang, gaya tarik dipikul oleh tulangan baja. Sedangkan pada struktur komposit, gaya tarik dipikul oleh elemen profil baja.. Kelebihan dari struktur komposit yang didapat dalam perencanaan adalah : (1) Penghematan berat struktur oleh baja. (2) Penampang profil balok yang lebih kecil. (3) Peningkatan kekakuan lantai. (4) Panjang bentang tertentu dapat lebih besar [1].

Salah satu kriteria dalam merancang struktur bangunan tinggi terutama untuk gedung adalah keselamatan (strength and ductile) dan kenyamanan (stiffness). Baja memiliki semua hal tersebut, dimana karakteristik baja identik dengan kekerasan, kekakuan, kekuatan tarik yang tinggi dan juga daktilitas [2]. Selain itu, sifat daktail yang dimiliki material baja dapat memberi perubahan bentuk yang besar sebelum mencapai kehancuran. Salah satu bangunan baja yang dirancang tahan gempa adalah bangunan baja dengan menggunakan sistem struktur berpengaku eksentris.

Sistem Rangka Berpengaku Eksentris (SRBE) adalah sistem dimana pengaku tidak terhubung ke perpotongan balok dan kolom melainkan terhubung ke balok dengan jarak “e” ke titik perpotongan balok dan kolom. Segmen balok pendek atau link ini memiliki daktilitas yang tinggi yang memastikan struktur memiliki perilaku inelastis serta penyerapan energi yang bagus [3].

Berdasarkan latar belakang diatas, akan dilakukan modifikasi gedung Apartemen Brooklyn Alam Sutera yang berlokasi di Tangerang. Apartemen Brooklyn Alam Sutera merupakan gedung dengan struktur utama beton bertulang dengan ketinggian 20 lantai. Dalam tugas akhir ini akan dimodifikasi stuktur utama gedung dengan menggunakan struktur baja komposit dengan sistem rangka berpengaku eksentris konfigurasi rangka inverted V-Braced.

\section{TINJAUAN PUSTAKA}

Sistem Rangka Berpengaku Eksentris (SRBE) merupakan suatu sistem struktur yang terdiri atas balok, kolom, dan 
pengaku dimana pengaku tersebut tidak terhubung ke perpotongan balok dan kolom melainkan terhubung ke balok dengan jarak "e" ke titik perpotongan balok dan kolom. Segmen balok pendek atau link ini memiliki daktilitas yang tinggi yang memastikan struktur memiliki perilaku inelastis serta penyerapan energi yang bagus [4]. Kinerja dari balok link tersebut akan lebih maksimal jika elemen-elemen di luar dari balok link tersebut direncanakan lebih kuat. Konsep perencanaan SRBE yang berdasarkan keseimbangan mekanisme kelelehan akan mencegah terjadinya cara keruntuhan yang tidak diinginkan yaitu elemen-elemen struktur tidak mengalami penurunan kekakuan dan kekuatan saat struktur menerima beban lateral.

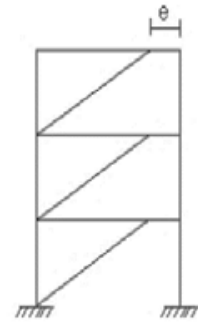

a. D-braced EBF

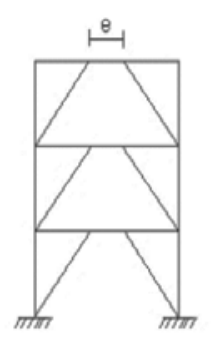

b. Split-K-braced EBF

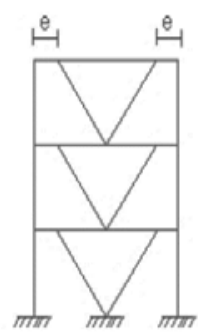

c. V-braced EBF
Gambar 1. Jenis-Jenis Konfigurasi SRBE ${ }^{[1]}$.

Tabel 1.

Klasifikasi Link[5]

\begin{tabular}{|c|c|c|c|c|}
\hline No & Panjang link & Jenis Link & Rotasi & $\begin{array}{c}\text { Jarak Pengaku } \\
\text { Maksimum }\end{array}$ \\
\hline \multirow{2}{*}{1} & $e \leq \frac{1,6 \times M p}{V_{p}}$ & Geser & 0,08 & 30. tw $-\mathrm{d} / 5$ \\
\cline { 3 - 5 } & & Murni & $<0,02$ & 52. tw $-\mathrm{d} / 5$ \\
\hline 2 & $\frac{1,6 \times M p}{V_{p}} \leq e \leq \frac{2,6 \times M p}{V_{p}}$ & Dominan Geser & & 1 dan 3 dipenuhi \\
\hline 3 & $\frac{2,6 \times M p}{V_{p}} \leq e \leq \frac{5 \times M p}{V_{p}}$ & Dominan Lentur & 0,02 & 1,5 bf dari tiap ujung link \\
\hline 4 & $e>\frac{5 \times M p}{V_{p}}$ & Lentur Murni & & Tidak memerlukan \\
\hline
\end{tabular}

Batang komposit adalah batang yang terdiri dari profil baja dan beton yang digabung bersama dan memikul beban tekan atau lentur. Batang yang memikul beban lentur umumnya disebut dengan balok komposit. Sedangkan batang yang memikul beban tekan umumnya disebut dengan kolom komposit. Aksi komposit timbul bila dua batang struktur pemikul beban seperti konstruksi lantai beton dan lantai baja penyanggah disambung secara integral dan meleleh secara satu kesatuan (Salmon dan Johnson, 2009).

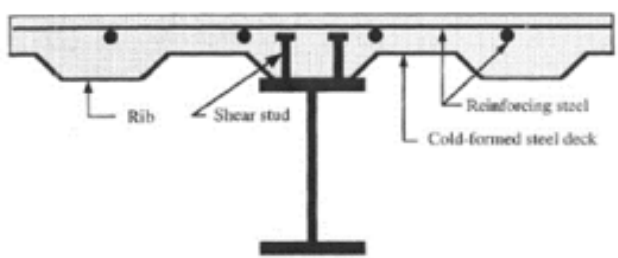

Gambar 3. Balok komposit dengan deck (alur gelombang sejajar sumbu balok)

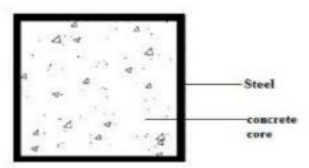

Gambar 4. Kolom Kompsot.
III. METODOLOGI

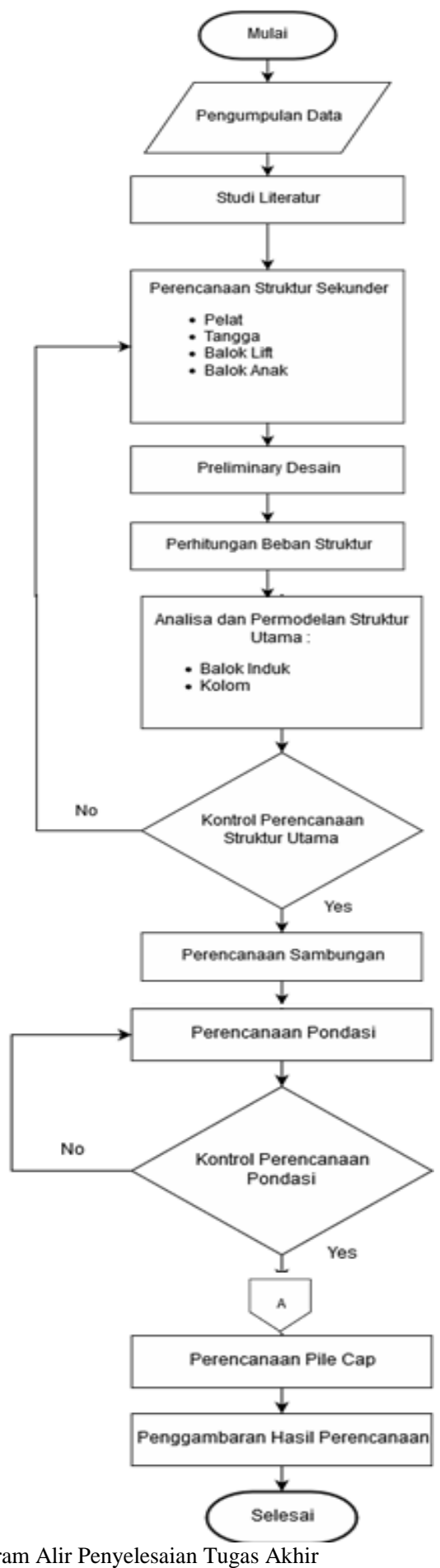

Gambar 4. Diagram Alir Penyelesaian Tugas Akhir

Pada penelitian ini akan dimodifikasi perencanaannya menggunakan material baja dengan data-data sebagai berikut :

1. Nama Gedung : Apartemen Brooklyn Alam Sutra

2. Lokasi Gedung : Pakualam, North Serpong, South

Tangerang City, Banten.

3. Fungsi Gedung : Gedung Apartemen

4. Material Struktur : Struktur baja dan beton komposit

5. Sistem Struktur : Rangka Berpengaku Eksentris (SRBE)

6. Tinggi Gedung : $\quad+70$ meter

7. Jumlah Lantai : 20 Lantai

8. Rencana Pondasi : BoredPile 


\section{HASIL DAN PEMBAHASAN}

\section{A. Perencanaan Struktur Sekunder}

1. Pelat Atap dan Lantai

Pelat lantai atap dan lantai apartemen direncanakan menggunakan bondek dari Super Floor Deck dengan tebal 0,75 mm. Hasil perhitungan struktur pelat ini tersaji pada tabel 2.

Tabel 2.

Rekapitulasi Perhitungan Pelat Atap

\begin{tabular}{cccc}
\hline \hline No & Bentang & Tulangan yang digunakan & Tebal $(\mathrm{mm})$ \\
\hline 1 & 1,75 & $\varnothing 6-350$ & 10 \\
2 & 2 & $\varnothing 8-200$ & 10 \\
3 & 3 & $\varnothing 8-200$ & 10 \\
4 & 1,5 & $\varnothing 6-400$ & 10 \\
\hline \hline
\end{tabular}

Tabel 3.

Rekapitulasi Perhitungan Pelat Lantai

\begin{tabular}{cccc}
\hline \hline No & Bentang & Tulangan yang digunakan & Tebal (mm) \\
\hline 1 & 1,75 & $\varnothing 8-300$ & 10 \\
2 & 2 & $\varnothing 8-400$ & 10 \\
3 & 3 & $\varnothing 8-300$ & 10 \\
4 & 1,5 & $\varnothing 6-400$ & 10 \\
\hline \hline
\end{tabular}

2. Perencanaan Balok Sekunder

Balok sekunder direncanakan menggunakan wide flange (WF) BJ-41. Hasil perhitungan balok sekunder tersaji pada Tabel 4 dan Tabel 5.

Tabel 4.

Dimensi Balok Sekunder Atap

\begin{tabular}{ccc}
\hline \hline No & Bentang $(\mathrm{m})$ & Profil \\
\hline 1 & 5,5 & WF 300.200.8.12 \\
2 & 2,2 & WF 250.175.7.11 \\
3 & 4,05 & WF 250.175.7.11 \\
4 & 5 & WF 300.150.5,5. 8 \\
\hline \hline
\end{tabular}

Tabel 5.

Dimensi Balok Sekunder Atap

\begin{tabular}{ccc}
\hline \hline No & Bentang $(\mathrm{m})$ & Profil \\
\hline 1 & 5,5 & $300 \times 200 \times 8 \times 12$ \\
2 & 2,2 & $200 \times 150 \times 6 \times 9$ \\
3 & 4,05 & $250 \times 175 \times 7 \times 11$ \\
4 & 5 & $300 \times 150 \times 5,5 \times 8$ \\
\hline \hline
\end{tabular}

3. Perencanaan Tangga dan Bordes

Tangga adalah sebuah konstruksi yang dirancang untuk menghubungi dua tingkat vertikal yang memiliki jarak satu sama lain.

Data Teknis Perencanaan Tangga

$\begin{array}{lll}\text { - } & \text { Mutu baja } & =\mathrm{BJ}-41 \\ \text { - } & \text { Tinggi antar lantai } & =300 \mathrm{~cm} \\ \text { - } & \text { Tinggi bordes } & =150 \mathrm{~cm} \\ \text { - } & \text { Panjang tangga } & =300 \mathrm{~cm} \\ \text { - Lebar tangga } & =160 \mathrm{~cm} \\ \text { - } & \text { Lebar bordes } & =200 \mathrm{~cm} \\ \text { - } & \text { Lebar injakan (i) } & =30 \mathrm{~cm} \\ \text { - } & \text { Tinggi Injakan (t) } & =15 \mathrm{~cm} \\ \text { - } & \text { Lebar pegangan tangga } & =10 \mathrm{~cm}\end{array}$

Tabel 6.

Dimensi Tangga

\begin{tabular}{|c|c|c|}
\hline No & Jenis Struktur & Ket. Profil \\
\hline 1 & Balok Utama Tangga & WF200.100.4,5.7 \\
\hline 2 & Balok Penumpu Tangga & WF200.150.6.9 \\
\hline 3 & Pelat Bordes & Bondek, $\mathrm{t}=9 \mathrm{~cm}$ \\
\hline 4 & Pelat Tangga & Bondek, $\mathrm{t}=9 \mathrm{~cm}$ \\
\hline
\end{tabular}

\section{Perencanaan Lift}

Pada bangunan ini menggunakan lift penumpang dengan data-data sebagai berikut (untuk lebih jelasnya lihat lampiran brosur lift):

- $\quad$ Tipe lift

: Passenger Elevators
- $\quad$ Merek

: HYUNDAI

- Kapasitas : 17 Orang / $1150 \mathrm{~kg}$

- $\quad$ Lebar pintu (opening width) : $1100 \mathrm{~mm}$

Dimensi Balok Penggantung Lift yaitu WF 600.300.12.20

\section{B. Permodelan Struktur}

1. Kontrol Beban Struktur

Karena besarnya beban gempa sangat dipengaruhi oleh berat dari struktur bangunan, maka perlu diketahui berat total bangunan untuk menentukan gaya geser statik. Berat dari bangunan berasal dari beban mati yang terdiri dari berat sendiri material-material bangunan dan elemen-elemen struktur, serta beban hidup yang diakibatkan oleh hunian atau penggunaan bangunan.

Berat total struktur perhitungan manual $=19142278,5 \mathrm{~kg}$

$$
\text { Berat total struktur ETABS } \quad=19184572 \mathrm{~kg}
$$

Sehingga diperoleh persentase:

$$
\frac{10478,5}{19.184 .572,35} \times 100 \%=0,055 \%<5 \%(O K)
$$

2. Kontrol Syarat 7.2.5.4 SNI 03-1726:2012

Berdasarkan pasal 7.2.5.4 SNI 03-1726:2012 [6], untuk batasan ketinggian dalam tabel 9 diijinkan untuk ditingkatkan dari 48m sampai $72 \mathrm{~m}$ untuk struktur dengan kategori seismik D atau E dengan syarat ;

- Struktur tidak boleh mempunyai ketidak beraturan torsi yang berlebihan seperti didefinisikan dalam Tabel 10 (ketidakberaturan struktur horisontal Tipe 1b) yang didefinisikan setiap ujung bangunan tidak boleh melebihi 1,4 kali simpangan antar lantai tingkat rata-rata di kedua ujung struktur.

- Semua bidang harus menahan tidak lebih dari 60 persen gaya gempa total dalam setiap arah, dengan mengabaikan pengaruh torsi tidak terduga.

Tabel 7.

Perbandingan torsi maksimum di tiap lantai

\begin{tabular}{cccccc}
\hline \hline Gempa & Lantai & Bidang X & Perbandingan & Bidang $Y$ & Perbandingan \\
\hline \multirow{2}{*}{$\mathrm{X}$} & 20 & 12,6 & \multirow{2}{*}{1,0210} & 31,5 & \multirow{2}{*}{1,0138} \\
& 19 & 11,4 & & 31,1 & \\
$\mathrm{Y}$ & 20 & 31,6 & \multirow{2}{*}{1,0143} & 39,075 & \multirow{2}{*}{1,0233} \\
\hline \hline
\end{tabular}

Tabel 8.

Perbandingan bidang gempa bresing dengan bidang keseluruhan.

\begin{tabular}{lrrrr}
\hline \hline Pemikul Gaya & \multicolumn{2}{c}{ Gempa X } & \multicolumn{2}{c}{ Gempa Y } \\
\cline { 2 - 5 } \multicolumn{1}{c}{ Geser } & \multicolumn{1}{c}{$\mathrm{Kg}$} & \multicolumn{1}{c}{$\%$} & $\mathrm{Kg}$ & \multicolumn{1}{c}{$\%$} \\
\hline SRBE & 188731,39 & 0,44 & 180127,45 & 0,41 \\
SRPM & $\mathbf{2 4 4 3 3 6 , 3 1}$ & $\mathbf{0 , 5 6}$ & $\mathbf{2 5 7 8 5 3 , 3 4}$ & $\mathbf{0 , 5 9}$ \\
Total & 433067,70 & 100,00 & 437980,79 & 100,00 \\
\hline \hline
\end{tabular}

3. Kontrol Partisipasi Massa

Partisipasi massa harus menyertakan jumlah ragam terkombinasi minimal 90\% dari massa aktual yang berasal dari masing-masing arah horizontal dan orthogonal yang ditinjau [6].

Tabel 9.

Kontrol Nilai Partisipasi Massa

\begin{tabular}{cccc}
\hline \hline OutputCase & Mode & SumUX & Sum UY \\
\hline Text & Text & Unitless & Unitless \\
Modal & 4 & 0,8345 & $\mathbf{0 , 9 0 3 8}$ \\
Modal & 5 & $\mathbf{0 , 9 0 8 9}$ & 0,904 \\
\hline \hline
\end{tabular}

4. Kontrol Waktu Getar Alami Fundamental

Perkiraan periode alami fundamental (Ta) dalam detik, harus ditentukan dengan persamaan berikut: 
$\mathrm{Ta}=\mathrm{Ct} . \mathrm{hn}^{\mathrm{x}} ; \mathrm{Ct}=0,0731 ; \mathrm{x}=0,75 ; \mathrm{hn}=70 \mathrm{~m}$

$\mathrm{Ta}=0,0731 \cdot 70^{0,75}=1,769$ detik

Dengan nilai $\mathrm{SD} 1=0,368$, maka $\mathrm{Cu}=1,4$

Sehingga periode sruktur yang diijinkan adalah :

$\mathrm{T}=\mathrm{Ta} . \mathrm{Cu}=1,769.1,4=2,476$ detik

Tabel 10.

Kontrol Waktu Getar Alami Fundamental

\begin{tabular}{lrr}
\hline \hline Case & Mode & \multicolumn{1}{c}{ Period } \\
\hline & & \multicolumn{1}{c}{ sec } \\
\hline Modal & 1 & $\mathbf{2 , 4 6 7}$ \\
Modal & 2 & 2,305 \\
$\ldots \ldots \ldots$. & $\ldots \ldots .$. & $\ldots \ldots \ldots .$. \\
Modal & 11 & 0,278 \\
Modal & 12 & 0,225 \\
\hline \hline
\end{tabular}

Dari tabel diatas Tc $=2,467 \mathrm{~s}$, maka berdasarkan kontrol aktu getar alami fundamental, nilai $\mathrm{T}$ masih lebih kecil dari Cu.T. Jadi analisis struktur memenuhi syarat.

5. Kontrol Nilai Akhir Respon Spektrum

Kombinasi respons untuk gaya geser dasar ragam dinamik $(\mathrm{Vt})$ harus lebih besar $85 \%$ dari gaya geser dasar statik $(\mathrm{V})$ atau $\left(\mathrm{V}_{\text {dinamik }} \geq 0,85 \mathrm{~V}_{\text {statik }}\right)$.

Tabel 11.

Kontrol Nilai Akhir Respon Spektrum

\begin{tabular}{lllc}
\hline \hline Ket & $\mathrm{V}_{\text {dinamik }}(\mathrm{kg})$ & $\mathrm{V}_{\text {statik }}(\mathrm{kg})$ & $\mathrm{V}_{\text {dinamik }} \geq \mathrm{V}_{\text {statik }}$ \\
\hline RSX & 418440,5 & \multirow{2}{*}{417610,5} & OK \\
RSY & 417679,7 & & OK \\
\hline \hline
\end{tabular}

6. Kontrol Simpangan (Drift)

Gempa menyebabkan struktur bertingkat rawan terhadap terjadinya simpangan horizontal (Drift). Dan apabila simpangan horizontal ini melebihi syarat aman yang telah ditentukan maka gedung akan mengalami keruntuhan dengan simpangan maksimum $60 \mathrm{~mm}$ dan $100 \mathrm{~mm}$.

Tabel 12.

Kontrol Simpangan Arah-Y Gempa Arah Y

\begin{tabular}{|l|r|r|r|r|r|}
\hline \multirow{3}{*}{ Lantai } & \multicolumn{1}{|c|}{$\begin{array}{c}\text { Tinggi } \\
\text { Lantai }\end{array}$} & \multicolumn{5}{|c|}{ Gempa Arah Y } \\
\cline { 2 - 6 } & \multicolumn{1}{|c|}{$\mathbf{Z i}$} & \multicolumn{4}{|c|}{ Simpangan Arah Y } \\
\cline { 2 - 6 } & $\mathbf{( m )}$ & $\boldsymbol{\delta 1} \mathbf{( m m )}$ & $\boldsymbol{\delta} \mathbf{2}-\boldsymbol{\delta 1} \mathbf{( m m )}$ & \multicolumn{1}{|c|}{$\mathbf{~ m m}$} & $\Delta_{\mathbf{a}} \mathbf{~ m m}$ \\
\hline Atap & 70 & 83,555 & 1,705 & 6,82 & 60 \\
\hline Lantai 19 & 67 & 81,85 & 2,008 & 8,032 & 60 \\
\hline Lantai 18 & 64 & 79,842 & 2,271 & 9,084 & 60 \\
\hline Lantai 17 & 61 & 77,571 & 2,535 & 10,14 & 60 \\
\hline Lantai 16 & 58 & 75,036 & 2,804 & 11,216 & 60 \\
\hline Lantai 15 & 55 & 72,232 & 2,932 & 11,728 & 60 \\
\hline Lantai 14 & 52 & 69,3 & 3,153 & 12,612 & 60 \\
\hline Lantai 13 & 49 & 66,147 & 3,355 & 13,42 & 60 \\
\hline Lantai 12 & 46 & 62,792 & 3,536 & 14,144 & 60 \\
\hline Lantai 11 & 43 & 59,256 & 3,697 & 14,788 & 60 \\
\hline Lantai 10 & 40 & 55,559 & 3,595 & 14,38 & 60 \\
\hline Lantai 9 & 37 & 51,964 & 3,797 & 15,188 & 60 \\
\hline Lantai 8 & 34 & 48,167 & 3,948 & 15,792 & 60 \\
\hline Lantai 7 & 31 & 44,219 & 4,103 & 16,412 & 60 \\
\hline Lantai 6 & 28 & 40,116 & 4,398 & 17,592 & 60 \\
\hline Lantai 5 & 25 & 35,718 & 8,15 & 32,6 & 100 \\
\hline Lantai 4 & 20 & 27,568 & 8,37 & 33,48 & 100 \\
\hline Lantai 3 & 15 & 19,198 & 8,055 & 32,22 & 100 \\
\hline Lantai 2 & 10 & 11,143 & 7,123 & 28,492 & 100 \\
\hline Lantai 1 & 5 & 4,02 & 4,02 & 16,08 & 100 \\
\hline
\end{tabular}

\section{Perhitungan Struktur Primer}

1. Link

Balok link direncanakan menggunakan profil WF 600 x 300 $\mathrm{x} 12 \mathrm{x} 27$. Dari hasil perhitungan didapat jenis link termasuk ke dalam link geser.

$$
\begin{aligned}
& \mathrm{e}=120 \mathrm{~cm}<1,6 . \mathrm{Mp} / \mathrm{Vp}=153,36 \mathrm{~cm} \\
& \alpha=0,056 \mathrm{radian}<\alpha \text { maks }=0,08 \text { radian } \\
& \mathrm{Nu}=3667 \mathrm{~kg}<0,15 \mathrm{Ny}=65437 \mathrm{~kg}
\end{aligned}
$$

$\mathrm{Vu}=59538 \mathrm{~kg}<\varnothing \mathrm{Vn}=88766 \mathrm{~kg}$

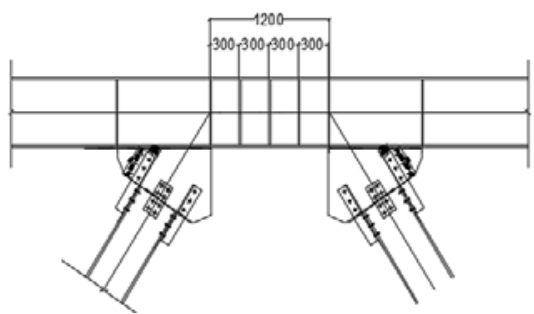

Gambar 5. Elemen Link dan Pengaku

Untuk pengaku dengan panjang link $<1,6$. Mp / Vp, harus direncanakan memiliki pengaku antara. Untuk $\alpha=0,04$ radian maka:

$$
\begin{aligned}
S & =54,36+\left(\frac{0,056-0,02}{0,08-0,02}\right) \cdot(50,76-24,36) \\
& =34,87 \mathrm{~cm}
\end{aligned}
$$

2. Balok diluar Link

Balok link direncanakan menggunakan profil WF 600 x 300 x 11 x 17. Berdasarkan SNI 03-1729:2002 [5]. Pasal 15.13.6.2, kuat perlu balok yang terletak diluar link harus ditentukan berdasarkan gaya- gaya yang ditimbulkan paling tidak 1,1 kali kuat geser nominal link sebesar Ry.Vn.

Kontrol interaksi geser lentur yang terjadi:

$$
\begin{aligned}
& \frac{M u}{\emptyset \cdot M n}+0,625 \frac{V u}{\emptyset \cdot V n} \leq 1,375 \\
& 1,342<1,375(\mathrm{OK})
\end{aligned}
$$

3. Bresing

Bresing direncanakan menggunakan profil WF 450 x 300 x 11 x 15. Berdasarkan SNI 03-1729:2002 Pasal 15.13.6.1, kuat kombinasi- aksial- dan lentur perlu pada batang bresing harus sebesar 1,25 Ry Vn.

$\mathrm{Vu}=1,25$. Ry. Vn [5]

$$
=166050 \mathrm{~kg}
$$

$P_{u}$ tekan $=P_{u}$ tarik $=\frac{V_{u}}{\sin \alpha}=\frac{166050}{0,853}=194485 \mathrm{~kg}$

Bressing tarik

$$
\begin{aligned}
\phi_{c} P_{n}= & \phi_{c} \cdot R_{y} \cdot F_{y} \cdot A g \\
= & 0,9 \cdot 1,5 \cdot 2500.135=430312 \mathrm{~kg} \\
& \phi_{c} P_{n}>P u \rightarrow 430312 \mathrm{~kg}>194485,4 \mathrm{~kg}(O K)
\end{aligned}
$$

Bresing tekan

$$
\begin{aligned}
\phi_{c} P_{n}=0,85 \cdot 1,1 \cdot R_{y} \cdot F_{y} \cdot A g / F_{c r} \\
=0,85 \cdot 1,1 \cdot 1,52500 \cdot 135 / 1,47=321870 \mathrm{~kg} \\
\phi_{c} P_{n}>P u \rightarrow 321870,3 \mathrm{~kg}>194485,4 \mathrm{~kg}(O K)
\end{aligned}
$$

4. Balok

Balok direncanakan menggunakan profil WF 600 x 300 x 12 x 17. Dari output ETABS 2016 diperoleh gaya dalam yang dipakai dalam desain adalah:

$$
\begin{aligned}
& \mathrm{Mu}=51173 \mathrm{~kg} \cdot \mathrm{m} \leq \varnothing \mathrm{Mn}=66575 \mathrm{~kg} \cdot \mathrm{m} \\
& \mathrm{Vu}=25989 \mathrm{~kg} \geq \varnothing \mathrm{Vn}=71577 \mathrm{~kg} \\
& \mathrm{f}^{0}=0,354 \mathrm{~cm} \leq \mathrm{f} \mathrm{ijin}=2,22 \mathrm{~cm}
\end{aligned}
$$

5. Kolom

Kolom direncanakan menggunakan profil HSS 700 x 700 x 28 x 28 dengan kontrol kuat nominal penampang sebagai berikut:

Rumus Interaksi:

$$
\frac{P u}{\varphi P n}=0,357>0,2 \rightarrow \text { Interaksi } 1
$$

Kontrol Interaksi "Balok - Kolom”

$$
\frac{P_{u}}{\emptyset P_{n}} \geq 0,2 \rightarrow \frac{P_{u}}{\emptyset P_{n}}+\frac{8}{9}\left(\frac{M_{u x}}{\emptyset_{b} M_{n x}}+\frac{M_{u y}}{\emptyset_{b} M_{n y}}\right) \leq 1,0 \text { [7] }
$$


$0,734 \leq 1,0(\mathrm{OK})$

Hasil seluruh perhitungan struktur primer akan disajikan pada Tabel 13.

Tabel 13.

Hasil Perhitungan Struktur Primer

\begin{tabular}{lc}
\hline \hline \multicolumn{1}{c}{ Elemen } & \multicolumn{1}{c}{ Dimensi } \\
\hline Link $X$ & WF 450.300.10.16 \\
Link $Y$ & WF 600.300.12.17 \\
Balok Diluar Link $X$ & WF 450.300.10.16 \\
Balok Diluar Link $Y$ & WF 600.300.12.17 \\
Bresing Arah X & WF 450.300.10.16 \\
Bresing Arah Y & WF 450.300.10.16 \\
Balok Induk Memanjang & WF 450.300.10.15 \\
Balok Induk Melintang & WF 500.300.11.15 \\
Kolom & HSS 600.600.25.25 \\
\hline \hline
\end{tabular}

\section{Perencanaan Sambungan}

1. Sambungan Struktur Sekunder

Pada perencanaan sambungan, direncanakan baut dengan mutu BJ50 dan pelat penyambung profil siku dengan mutu BJ41. Hasil perhitungan sambungan struktur sekunder terlampir pada Tabel 14.

Tabel 14.

Sambungan Struktur Sekunder

\begin{tabular}{lllll}
\hline \hline \multicolumn{2}{c}{ Elemen } & Profil Siku & D (mm) & $\mathrm{n} \mathrm{(jb)}$ \\
\hline $\begin{array}{l}\text { Balok anak } \\
\text { lantai -balok } \\
\text { Induk }\end{array}$ & Badan B.Anak & L60.60.6 & 16 & 2 \\
\hline $\begin{array}{l}\text { Balok utama } \\
\text { tangga }\end{array}$ & $\begin{array}{l}\text { Badan B.Induk } \\
\text { Tangga }\end{array}$ & L60.60.6 & 16 & 2 \\
$\begin{array}{l}\text { penumpu } \\
\text { tangga }\end{array}$ & $\begin{array}{l}\text { Badan } \\
\text { B.Penumpu } \\
\text { Tangga }\end{array}$ & L60.60.6 & 8 & 3 \\
\hline $\begin{array}{l}\text { Balok } \\
\text { penumpu } \\
\text { tangga } \\
\text { kolom }\end{array}$ & $\begin{array}{l}\text { Badan } \\
\text { B.Penumpu }\end{array}$ & L60.60.6 & 8 & 3 \\
\hline
\end{tabular}

2. Sambungan Struktur Primer

Pada perencanaan sambungan, direncanakan baut dengan mutu A490, Mutu las $\mathrm{FE}_{70 \mathrm{xx}}$ dan $\mathrm{FE}_{110 \mathrm{xx}}$, dan pelat penyambung mutu BJ-41. Hasil perhitungan sambungan struktur primer tersaji pada Tabel 15.

Tabel 15.

Sambungan Struktur Primer

\begin{tabular}{|c|c|c|c|c|}
\hline Elemen & $\begin{array}{l}\text { D Badan } \\
\text { (mm) }\end{array}$ & $\begin{array}{c}\mathrm{N} \text { badan } \\
\text { (buah) }\end{array}$ & $\begin{array}{c}\text { D sayap } \\
(\mathrm{mm})\end{array}$ & $\begin{array}{c}\text { N sayap } \\
\text { (buah) }\end{array}$ \\
\hline $\begin{array}{l}\text { Balok diluar Link X dan } \\
\text { Kolom }\end{array}$ & 20 & 4 & 30 & 12 \\
\hline $\begin{array}{l}\text { Balok diluar Link Y dan } \\
\text { Kolom }\end{array}$ & 20 & 4 & 30 & 14 \\
\hline Bresing X & 24 & 8 & 24 & 8 \\
\hline Bresing Y & 24 & 8 & 24 & 12 \\
\hline Balok Induk X dan Kolom & 20 & 3 & 30 & 10 \\
\hline Balok Induk Y dan Kolom & 20 & 4 & 30 & 14 \\
\hline Antar Kolom & \multicolumn{4}{|c|}{ Las tumpul penetrasi penuh $1,6 \mathrm{~cm}$} \\
\hline Kolom - Base Plate & T Plat $=$ & $60 \mathrm{~mm}$ & $\mathrm{~N}$ angkur & 8M22 \\
\hline
\end{tabular}

\section{E. Perhitungan Struktur Bawah}

1. Pondasi Tiang Pancang

Pondasi yang digunakan pada perencanaan gedung perkantoran berasal dari borepile dengan desain ;

- Diameter tiang $\quad: 800 \mathrm{~mm}$

- Tebal tiang $\quad: 50 \mathrm{~mm}$

- Berat : $393 \mathrm{~kg} / \mathrm{m}$

- $\quad$ Momen maksimum $\quad: 19,1 \mathrm{tm}$
Gambar 6. _Diagram Momen pada Borepile

Daya dukung ijin dari satu tiang pancang yang berdiri sendiri adalah

$$
\begin{aligned}
& P_{i j i n 1 \text { tiang }}=176,7 t \\
& P_{i j i n 1 \text { tiang }} \text { pakai }=164 \text { ton }
\end{aligned}
$$

Kontrol beban tetap

$$
\mathrm{P}_{\max }=165 \text { ton }<\mathrm{Q}_{\mathrm{ijin}}=176,7 \text { ton }(\mathrm{OK})
$$

2. Perencanaan Poer

Untuk penulangan lentur, poer dianalisa sebagai balok kantilever dengan perletakan jepit pada kolom. Dan beban yang bekerja adalah beban terpusat di tiang kolom yang menyebabkan reaksi pada tanah dan berat sendiri poer [8]. Berikut adalah hasil perhitungan untuk dimensi poer : Tabel 16. Dimensi Poer dan jumlah Bore Pile

\begin{tabular}{cccc}
\hline \hline \multirow{2}{*}{ Tipe Pile Cap } & \multirow{2}{*}{ Dimensi } & \multicolumn{2}{c}{ Jumlah Pile } \\
\cline { 3 - 4 } & & X & Y \\
\hline 1 & $3200 \times 3200 \times 1200$ & 2 & 2 \\
2 & $3200 \times 6400 \times 1200$ & 2 & 4 \\
3 & $2400 \times 3600 \times 1200$ & 2 & 3 \\
\hline \hline
\end{tabular}

Tabel 17. Jumlah Tulangan pada Pile Cap

\begin{tabular}{cccccc}
\hline \hline \multirow{2}{*}{$\begin{array}{c}\text { Tipe Pile } \\
\text { Cap }\end{array}$} & \multirow{2}{*}{ Dimensi } & \multicolumn{2}{c}{ Penulangan Arah } & \multicolumn{2}{c}{ Penulangan Arah } \\
\cline { 2 - 6 } & & Atas & Bawah & Atas & Bawah \\
\hline 1 & $3200 \times 3200 \times 1200$ & 7D25 & 7D29 & 7D25 & 7D29 \\
2 & $3200 \times 4800 \times 1200$ & 6D20 & 7D29 & 6D20 & 7D29 \\
3 & 2400x3600x1200 & 6D20 & 7D29 & 12D18 & 7D29 \\
\hline \hline
\end{tabular}

3. Perencanaan Kolom Pedestal

Besarnya gaya - gaya dalam kolom diperoleh dari hasil analisis ETABS 2016 adalah:

$$
\begin{aligned}
& \mathrm{Mu}=25478,76 \mathrm{~kg} \cdot \mathrm{m} \\
& \mathrm{Pu}=522843,95 \mathrm{~kg}=5228439,5 \mathrm{~N} \\
& \mathrm{Vu}=9311,6 \mathrm{~kg}=93316 \mathrm{~N}
\end{aligned}
$$

Dimensi kolom pedestal $800 \mathrm{~mm} \times 800 \mathrm{~mm}$.

As $=0,0101.800 .725,5=7371,08 \mathrm{~mm}^{2}$

Dipasang tulangan 16D25, As $=7371,08 \mathrm{~mm}^{2}$ Dipasang merata 4 sisi dengan sengkang $\varnothing 10-300$.

4. Perencanaan Tie Beam

Tie Beam direncanakan menggunakan tulangan baja, hal tersebut dilakukan karena Tie Beam menerima kombinasi beban aksial tekan dan lentur dimensi 400x600 mm.

$$
\begin{array}{ll}
\text { Gaya aksial kolom } & =566897 \mathrm{~kg} \\
\mathrm{P}_{\mathrm{u}} \text { sloof } & =10 \% \times 566897 \mathrm{~kg} \\
& =56689,7 \mathrm{Kg}=566897 \mathrm{~N}
\end{array}
$$

Dari perhitungan didapat $\rho=0,0129$

Dipasang tulangan $=8 \mathrm{D} 22\left(A_{s}=3096 \mathrm{~mm}^{2}\right)$ dan sengkang $\varnothing 10-300 \mathrm{~mm}$. 


\section{KESIMPULAN/RINGKASAN}

\section{A. Kesimpulan}

1. Hasil perhitungan pada struktur sekunder telah memenuhi syarat terhadap kontrol kuat penampang, kontrol geser dan lendutan yang mengacu kepada SNI 1729:2015 [7].

2. Dari kontrol yang dilakukan, kontrol yang direncanakan berada di kota Tangerang telah memenuhi syarat yang terdapat pada SNI 1729:2015 (analisis struktur dapat digunakan)

3. Hasil analisa struktur primer yang dilakukan telah memenuhi syarat terhadap kontrol kuat penampang, kontrol geser, kontrol sudut rotasi link, kontrol interaksi geser lentur dan lendutan.

4. Perhitungan pada struktur bawah telah memenuhi persyaratan dimensi dan kontrol akibat pons.

\section{B. Saran}

Diharapkan dilakukan studi yang mempelajari tentang perencanaan struktur Eccentrically Braced Frames (EBF) lebih dalam dengan mempertimbangkan aspek teknis, ekonomis, dan estetika dengan tetap mengacu kepada aturan yang berlaku.

\section{DAFTAR PUSTAKA}

[1] A. Fauzi, "Modifikasi Perencanaan menggunakan Sistem Rangka Bresing Konsentris Khusus pada Gedung Apartemen Metropolis," Surabaya, 2013.

[2] E. P. Popov, Mechanics of Material 2nd edition. New Jersey: PrenticeHall, 1978.

[3] I. Fihari, "Analisis Pelat Buhul Struktur Rangka Baja Berpengaku Eksentrik,” Yogyakarta, 2010.

[4] American Institute of Steel Construction, "Seismic Provision for Structural Steel Buildings,” 2010

[5] Badan Standardisasi Nasional, "SNI 03-1729-2002: Tata Cara Perencanaan Struktur Baja Untuk Bangunan Gedung,” Jakarta, 2002.

[6] Badan Standardisasi Nasional, "SNI 03-1726-2012 Tata Cara Perencanaan Ketahanan Gempa Untuk Bangunan Gedung,” Jakarta, 2012.

[7] Badan Standarisasi Nasional, "Spesifikasi untuk Bangunan Baja Struktural (SNI 03-1729-2015),” Bandung, 2015.

[8] H. Wahyudi, “Daya Dukung Pondasi Dalam,” Surabaya, 2013. 